\title{
Contribution of T-Type Calcium Channels to Spinal Cord Injury-Induced Hyperexcitability of Nociceptors
}

\author{
Justas Lauzadis, ${ }^{1}$ Huilin Liu, ${ }^{2}$ Yong Lu, ${ }^{2}$ Mario J. Rebecchi, ${ }^{2}$ Martin Kaczocha, ${ }^{2}$ and Michelino Puopolo ${ }^{2}$ \\ ${ }^{1}$ Graduate Program in Molecular and Cellular Pharmacology, Department of Pharmacology, Stony Brook Medicine, Stony Brook, NY 11794, and \\ ${ }^{2}$ Department of Anesthesiology, HSC L4-076, Stony Brook Medicine, Stony Brook, NY 11794
}

\begin{abstract}
A hyperexcitable state and spontaneous activity of nociceptors have been suggested to play a critical role in the development of chronic neuropathic pain following spinal cord injury (SCI). In male rats, we employed the action potential-clamp technique to determine the underlying ionic mechanisms responsible for driving SCI-nociceptors to a hyperexcitable state and for triggering their spontaneous activity. We found that the increased activity of low voltage activated T-type calcium channels induced by the injury sustains the bulk $(\sim 60-70 \%)$ of the inward current active at subthreshold voltages during the interspike interval in SCI-nociceptors, with a modest contribution $(\sim 10-15 \%)$ from tetrodotoxin (TTX)-sensitive and TTX-resistant sodium channels and hyperpolarization-activated cyclic nucleotide-gated $(\mathrm{HCN})$ channels. In current-clamp recordings, inhibition of T-type calcium channels with $1 \mu \mathrm{M}$ TTA-P2 reduced both the spontaneous and the evoked firing in response to current injections in SCI-nociceptors to a level similar to sham-nociceptors. Electrophysiology in vitro was then combined with the conditioned place preference (CPP) paradigm to determine the relationship between the increased activity of T-type channels in SCI-nociceptors and chronic neuropathic pain following SCI. The size of the interspike T-type calcium current recorded from nociceptors isolated from SCI rats showing TTA-P2-induced CPP (responders) was $\sim 6$ fold greater than the interspike T-type calcium current recorded from nociceptors isolated from SCI rats without TTA-P2-induced CPP (non-responders). Taken together, our data suggest that the increased activity of T-type calcium channels induced by the injury plays a primary role in driving SCI-nociceptors to a hyperexcitable state and contributes to chronic neuropathic pain following SCI.
\end{abstract}

Key words: chronic neuropathic pain; conditioned place preference paradigm; nociceptors; spinal cord injury; T-type calcium channels

Significance Statement

Chronic neuropathic pain is a major comorbidity of spinal cord injury (SCI), affecting up to $70-80 \%$ of patients. Anticonvulsant and tricyclic antidepressant drugs are first line analgesics used to treat SCI-induced neuropathic pain, but their efficacy is very limited. A hyperexcitable state and spontaneous activity of SCI-nociceptors have been proposed as a possible underlying cause for the development of chronic neuropathic pain following SCI. Here, we show that the increased activity of T-type calcium channels induced by the injury plays a major role in driving SCI-nociceptors to a hyperexcitable state and for promoting their spontaneous activity, suggesting that T-type calcium channels may represent a pharmacological target to treat SCI-induced neuropathic pain.

\section{Introduction}

Chronic neuropathic pain affects up to $70-80 \%$ of patients living with spinal cord injury (SCI; Finnerup et al., 2001, 2014; Siddall and Loeser, 2001; Siddall et al., 2003; Cragg et al., 2015). SCI-

\footnotetext{
Received Feb. 26, 2020; revised July 22, 2020; accepted July 30, 2020.

Author contributions: M.J.R., M.K., and M.P. designed research; J.L., H.L., and L.Y. performed research; J.L. and M.P. analyzed data; M.J.R., M.K., and M.P. wrote the paper.

This work was supported by the Department of Defense Grant W81XWH1810746 (to M.P.).

The authors declare no competing financial interests.

Correspondence should be addressed to Michelino Puopolo at michelino.puopolo@stonybrook.edu.

https://doi.org/10.1523/JNEUROSCI.0517-20.2020

Copyright $\odot 2020$ the authors
}

induced neuropathic pain (SCI-pain) is often lifelong and in many cases therapeutically intractable (Störmer et al., 1997; Finnerup et al., 2001, 2014; Siddall and Loeser, 2001; Siddall et al., 2003; Werhagen et al., 2004; Jensen et al., 2007; Finnerup, 2013; Cohen and Mao, 2014; Walters, 2014; Andresen et al., 2016), leading to severe decline of quality of life and increased risks for depression, anxiety, and addiction (Cragg et al., 2015; Andresen et al., 2016; Velly and Mohit, 2018).

The mechanisms that promote the development of SCI-pain are poorly understood, resulting in poor success in managing SCI-pain. A hyperexcitable state of injured nociceptors is common to various neuropathic pain conditions (Dib-Hajj et al., 
2010; Waxman and Zamponi, 2014), suggesting that it may play a critical role in the development of chronic neuropathic pain following nerve injury. A hyperexcitable state and spontaneous activity of nociceptors also develop following contusion of the spinal cord (Hains et al., 2003; Carlton et al., 2009; Bedi et al., 2010; Walters, 2012; Wu et al., 2013, 2017; Yang et al., 2014). In rodent models of SCI, in vivo and in vitro electrophysiological recordings from $\mathrm{A} \delta$-fiber and $\mathrm{C}$-fiber have provided strong evidence that SCI-nociceptors exhibit a hyperexcitable state and increased spontaneous activity from $3 \mathrm{~d}$ up to eight months following the injury (Carlton et al., 2009; Bedi et al., 2010). Rats subjected to SCI develop chronic neuropathic pain phenotypes (Bedi et al., 2010; Detloff et al., 2013; Ritter et al., 2015), and there is a strong relationship between the severity of pain and the incidence of spontaneous activity of SCI-nociceptors (Bedi et al., 2010). Taken together, these studies point to a strong relationship between the increased spontaneous activity of SCI-nociceptors and the development of SCI-pain.

The spontaneous activity of SCI-nociceptors is retained for at least $1 \mathrm{~d}$ in nociceptors maintained in primary cultures in vitro (Bedi et al., 2010). This offers the unique opportunity to employ in vitro electrophysiology to identify the underlying ionic mechanisms and the key ion channels responsible for driving SCI-nociceptors to a hyperexcitable state and for promoting their spontaneous activity. Tetrodotoxin (TTX)-sensitive and TTX-resistant sodium channels sustain the bulk of inward current during the upstroke of the action potential in small diameter dorsal root ganglia neurons (DRGs) (Renganathan et al., 2001; Blair and Bean, 2002; Rush et al., 2007), but it is unknown whether they contribute also inward current at subthreshold voltages necessary to drive the spontaneous activity of injured nociceptors. To address this critical mechanistic question, we employed the action potential-clamp technique (Raman and Bean, 1999; Puopolo et al., 2007) in DRGs sensitive to capsaicin (TRPV1positive; Caterina et al., 1997), to directly identify the key ion channels responsible for driving SCI-nociceptors to a hyperexcitable state. In contrast to previous studies in which SCI-induced changes in NaV1.8, Kv3.4, and TRPV1 channels were suggested to contribute to the hyperexcitable state of SCI-nociceptors (Yoshimura and de Groat, 1997; Wu et al., 2013; Yang et al., 2014; Ritter et al., 2015), our direct approach showed that the increased activity of low voltage-activated T-type calcium channels induced by the injury plays a primary role in driving SCInociceptors to a hyperexcitable state and for promoting their spontaneous activity. Our data show that the T-type channels provide the bulk $(\sim 60-70 \%)$ of inward current active at subthreshold voltages during the interspike interval in SCI-nociceptors. Inhibition of T-type calcium channels with TTA-P2 reversed the hyperexcitable state of SCI-nociceptors in vitro and reduced ongoing pain in vivo.

\section{Materials and Methods}

\section{Animals}

Sprague Dawley rats (male, 300-350 g) were used in this study. All procedures were performed in strict accordance with the guidelines of the International Association for the Study of Pain and were approved by Stony Brook University Institutional Animal Care and Use Committee. Rats were deeply anesthetized with isoflurane before decapitation.

$S C I$

Animals were anesthetized with a mixture of ketamine/xylazine (75 and $5 \mathrm{mg} / \mathrm{kg}$, respectively, i.p.). Once there was no longer a paw pinch response, the hairs of the thoracic and lumbar spinal region were sheared. A midline incision was made on the back, and the paravertebral muscles at the level of the T9-T11 vertebrae were gently separated from the spinous processes of the vertebrae and retracted. The T9 and T11 dorsal processes were braced to stabilize the spine, and the dorsal process of T10 was removed with bone rongeur to expose the spinal cord. SCI was then performed by spinal cord contusion by using an Infinite Horizon Impactor (Precision Systems). A steel rod (2.5 $\mathrm{mm}$ in diameter) attached to the impactor was used to apply a force of 150 kilodynes (1-s dwelling time) to the dorsal aspect of the spinal cord to generate the injury. Following the injury, the muscles were sutured, and the skin wound was closed with metal wound clips and treated with betadine solution. Animals received baytril $(2.5 \mathrm{mg} / \mathrm{kg}$, i.m.) twice daily for $7 \mathrm{~d}$, and buprenorphine $(0.05 \mathrm{mg} / \mathrm{kg}$, i.m.) twice daily for $3 \mathrm{~d}$. Manual expression of the bladder was performed twice daily until voiding was regained (usually 10-12 d following the spinal impact).

\section{Sham laminectomy}

The surgical procedure was similar to that described above for the SCI, but animals received only the laminectomy at T10 without the contusion.

\section{Recovery of hindlimb motor function [Basso, Beattie, Bresnahan (BBB)} score]

The BBB scale (Basso et al., 1995, 1996) was used for measuring motor deficits following SCI. Animals in the SCI and sham groups were assessed for hindlimb motor function while moving freely in a circular enclosure ( $1 \mathrm{~m}$ diameter). For the SCI group, only rats with a BBB score of zero at days $0-1$ postinjury were included in the study. For the sham group, only rats with a $\mathrm{BBB}$ score of 21 at days $0-1$ postlaminectomy and with no signs of motor impairment were included in the study.

\section{Histology}

Three months following the injury, rats were deeply anesthetized with a mix of $100 \mathrm{mg} / \mathrm{kg}$ ketamine plus and $10 \mathrm{mg} / \mathrm{kg}$ xylazine, intraperitoneally, and transcardially perfused with saline followed by $4 \%$ paraformaldehyde (PFA) in $0.1 \mathrm{M}$ PBS, pH 7.4. The spinal cord was dissected out and immersed in the same fixative overnight at $4^{\circ} \mathrm{C}$ followed by immersion in $30 \%$ sucrose in $0.1 \mathrm{M} \mathrm{PB}$ for $48 \mathrm{~h}$ for cryoprotection. The tissues were embedded in Tissue-Tek O.C.T. Compound (Sakura) and frozen using a liquid nitrogen-chilled isopentane bath. Cryostat sections of $20 \mu \mathrm{m}$ thick were then mounted on gelatin coated RITE-ON slides (Thermo Fisher Scientific). Histologic analysis was conducted at three different levels of the spinal cord: rostral to the site of impact (T8-T9), at the site of impact (T10), and caudal to the site of impact (L1-L2). For Luxol Fast Blue staining, slides were placed in $95 \%$ ethanol for $10 \mathrm{~min}$, rinsed with distilled water for $2 \mathrm{~min}$, and then incubated in $0.1 \%$ Luxol Fast Blue for $12 \mathrm{~h}$ at $65^{\circ} \mathrm{C}$. Sections were then rinsed in $95 \%$ ethanol for $1 \mathrm{~min}$ and differentiated in $0.05 \%$ lithium carbonate $(1 \mathrm{~min})$ followed by $70 \%$ ethanol ( $1 \mathrm{~min}$ ) and washed in distilled water (30 s). Differentiation was repeated until gray matter was clear and defined. Slides were then placed in $0.1 \%$ Cresyl Violet (40 s) and rinsed in distilled water. Differentiation was done with 5-10 dips into 95\% ethanol. Slides were then mounted on a coverslip with Aqua-mount (Thermo Fisher Scientific), and pictures were taken immediately after. For Toluidine Blue staining, slides were placed in $0.1 \%$ Toluidine Blue solution ( $3 \mathrm{~min}$ ) followed by $10 \mathrm{~s}$ in $100 \%$ ethanol and two washes with xylene ( $3 \mathrm{~min}$ each). Slides were then mounted on a coverslip using Krystalon Mounting Medium (HARLECO), and pictures were taken immediately after.

\section{Dissociated DRGs}

Rats were deeply anesthetized with isoflurane and decapitated. A dorsal laminectomy was performed to expose the lumbar aspect of the spinal cord and DRG. DRG (L3, L4, and L5) were pulled out and placed in a cold $\mathrm{Ca}^{2+}, \mathrm{Mg}^{2+}$-free Hanks' solution containing the following: $137 \mathrm{mM}$ $\mathrm{NaCl}, 5.3 \mathrm{~mm} \mathrm{KCl}, 0.33 \mathrm{~mm} \mathrm{Na}_{2} \mathrm{HPO}_{4}, 0.44 \mathrm{~mm} \mathrm{KH}_{2} \mathrm{PO}_{4}, 5$ mM HEPES, and $5.5 \mathrm{~mm}$ glucose; $\mathrm{pH} 7.4$ with $\mathrm{NaOH}$. Ganglia were cut in half and incubated for $20 \mathrm{~min}$ at $34^{\circ} \mathrm{C}$ in $\mathrm{Ca}^{2+}, \mathrm{Mg}^{2+}$-free Hanks' solution containing $20 \mathrm{U} / \mathrm{ml}$ Papain (Worthington Biochemical) and $5 \mathrm{~mm}$ DL- 
A
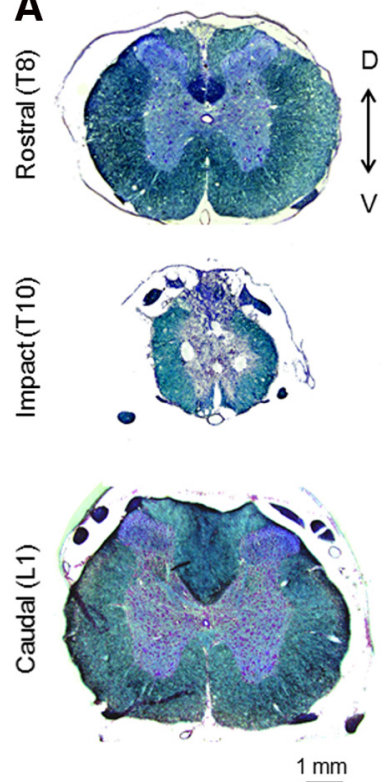

B

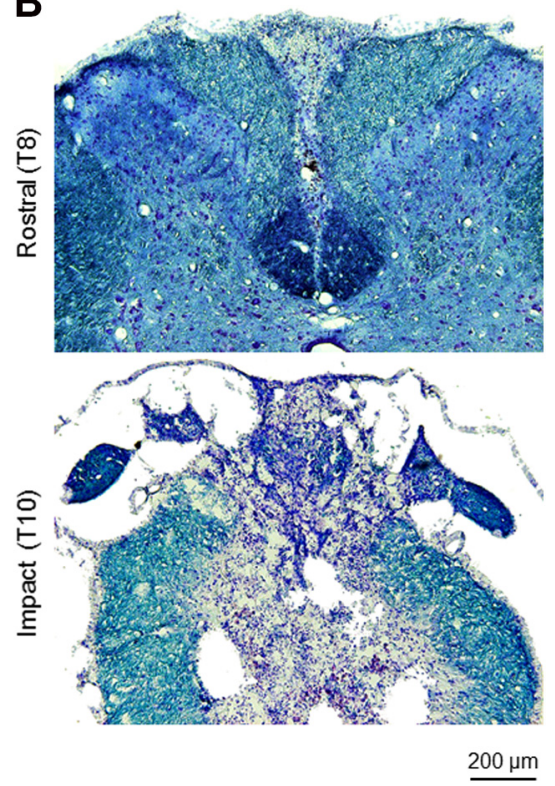

Figure 1. Spinal cord contusion. Representative sections of the spinal cord taken from a SCl rat at three months postinjury and stained with luxol fast blue and cresyl violet. $\boldsymbol{A}$, Sections of the spinal cord taken at a rostral site (T8), at the impact site (T10), and at a caudal site (L1). Magnification, $4 \times$. B, Sections of the rostral and impact sites shown at $10 \times$ magnification.

potential-clamp technique (Raman and Bean, 1999; Puopolo et al., 2005, 2007). Spontaneous activity was first recorded from a spontaneously active SCI-nociceptor and then used as voltage command in voltage clamp for all the recorded neurons. A segment of spontaneous activity with regular firing was chosen to facilitate the analysis of the interspike currents. To isolate sodium and calcium currents, a Cs-based internal solution was used containing the following: 110 mM Cs-methanesulfonate, 15 mM TEA-Cl, 10 $\mathrm{mm} \mathrm{NaCl}, 2 \mathrm{~mm} \mathrm{MgCl}_{2}, 10 \mathrm{~mm}$ EGTA, 10 mM HEPES, 14 mM Tris-creatine $\mathrm{PO}_{4}, 4 \mathrm{~mm}$ Mg-ATP, and 0.3 mм Na-GTP; pH 7.2 with $\mathrm{CsOH}$. The standard external solution was a modified Tyrode's solution. To isolate the sodium current, the Tyrode's solution contained the following: $151 \mathrm{~mm} \mathrm{NaCl}, 2 \mathrm{~mm}$ $\mathrm{CaCl}_{2}, 10 \mathrm{~mm}$ HEPES, and $13 \mathrm{~mm}$ glucose; $\mathrm{pH} 7.4$ with $\mathrm{NaOH}$. The TTX-sensitive sodium current was isolated as the current sensitive to $1 \mu \mathrm{M}$ TTX added to the external solution. The TTX-resistant sodium current was isolated as the current sensitive to $1 \mu \mathrm{M}$ A803467 applied on top of $1 \mu \mathrm{M}$ TTX. To isolate the calcium current, the Tyrode's solution contained the following: $151 \mathrm{~mm}$ TEA$\mathrm{Cl}, 2 \mathrm{~mm} \mathrm{CaCl} 2,10 \mathrm{~mm}$ HEPES, and $13 \mathrm{~mm}$ glucose; $\mathrm{pH} 7.4$ with TEA-OH. The total cal-

cysteine. Ganglia were then treated for $20 \mathrm{~min}$ at $34^{\circ} \mathrm{C}$ with $3 \mathrm{mg} / \mathrm{ml} \mathrm{col-}$ lagenase (Type I, Sigma-Aldrich) and $4 \mathrm{mg} / \mathrm{ml}$ Dispase II (Boehringer Mannheim) in in $\mathrm{Ca}^{2+}, \mathrm{Mg}^{2+}$-free Hanks' solution. Ganglia were then washed with Leibovitz's L-15 medium (Invitrogen). Individual cells were dispersed by mechanical trituration using fire-polished Pasteur pipettes with decreasing bore size and plated on glass coverslip treated with 30$50 \mu \mathrm{g} / \mathrm{ml}$ poly-D-lysine. Cells were incubated in the L-15 solution supplemented with $10 \mathrm{ng} / \mathrm{ml}$ of NGF at $34^{\circ} \mathrm{C}$ (in $5 \% \mathrm{CO}_{2}$ ) and used within $24 \mathrm{~h}$. Small DRGs (diameters $<27 \mu \mathrm{m}$ ) were chosen for recording. Small DRGs were selected by measuring the diameter from images captured to a computer by a CCD camera (Oly-150, Olympus Imaging America Inc.) using a video acquisition card (dP dPict Imaging). Cell capacitance was measured by integrating the average of 5-10 capacitive currents in response to a $-5 \mathrm{mV}$ step from $-80 \mathrm{mV}$ filtered at $10 \mathrm{kHz}$ and acquired at $50 \mathrm{kHz}$.

\section{Cell classification}

At the end of each experiment, DRGs were tested for capsaicin sensitivity, and only those responding to capsaicin (TRPV1-positive, 69\% of those tested), corresponding to a subset of nociceptors (Cardenas et al., 1995; Caterina et al., 1997; Petruska et al., 2000), were included in the analysis. Because nociceptors are neurochemically and functionally distinct (Nagy and Hunt, 1982; Silverman and Kruger, 1990; Stucky and Lewin, 1999; Dirajlal et al., 2003), a further classification was made by testing the ability of TRPV1-positive DRGs to bind the isolectin B4 (IB4) FITC-conjugate and classified as peptidergic [IB4(-)] or non-peptidergic [IB4(+)]. The majority (99\%) of TRPV1-positive DRGs included in the study were also IB4 $(+)$.

\section{Electrophysiology}

Whole-cell recordings were made with a Multiclamp 700B amplifier (Molecular Devices). Patch pipettes were pulled from borosilicate glass (A-M Systems) using a Sutter P97 puller (Sutter Instrument). The resistance of the patch pipette was $1.8-2.5 \mathrm{M} \Omega$ when filled with the standard internal Cs-based or K-based solution. The shank of the patch pipette was wrapped with parafilm to reduce pipette capacitance. In whole-cell mode, the capacity current was reduced by using the amplifier circuitry. To reduce voltage errors, $70-80 \%$ of series resistance compensation was applied. In voltage-clamp experiments, sodium, calcium, and Ih currents active during the interspike interval were isolated by using the action cium current was isolated as the current sensitive to replacement of 2 $\mathrm{mm} \mathrm{Ca}^{2+}$ with $2 \mathrm{~mm} \mathrm{Co}^{2+}$ in the external solution. The T-type, N-type, $\mathrm{P} / \mathrm{Q}$-type, and L-type calcium currents were isolated as the currents sensitive to $1 \mu \mathrm{M}$ TTA-P2, $1 \mu \mathrm{M} \omega$-conotoxin GVIA, $500 \mathrm{~nm} \omega$-agatoxin IVA, and $2 \mu \mathrm{m}$ nimodipine, respectively. To isolate the Ih current, the internal solution contained the following: $125 \mathrm{~mm}$ K-methanesulfonate, 10 mм NaCl, 2 mм $\mathrm{MgCl}_{2}$, 10 mм EGTA, 10 mм HEPES, 14 mм Tris-creatine $\mathrm{PO}_{4}, 4 \mathrm{~mm} \mathrm{Mg-ATP}$, and $0.3 \mathrm{~mm} \mathrm{Na-GTP;} \mathrm{pH} 7.2$ with $\mathrm{KOH}$. The Tyrode's solution contained the following: $151 \mathrm{~mm} \mathrm{NaCl}, 2 \mathrm{~mm} \mathrm{CaCl}$, $10 \mathrm{~mm}$ HEPES, and $13 \mathrm{~mm}$ glucose; $\mathrm{pH} 7.4$ with $\mathrm{NaOH}$. The Ih current was isolated as the current sensitive to $3 \mathrm{mM} \mathrm{Cs}^{+}$in the external solution. For current-clamp recordings, the internal solution contained the following: $125 \mathrm{~mm}$ K-methanesulfonate, $10 \mathrm{~mm} \mathrm{NaCl}, 2 \mathrm{~mm} \mathrm{MgCl}_{2}, 0.1 \mathrm{~mm}$ EGTA, 10 mM HEPES, 14 mM Tris-creatine $\mathrm{PO}_{4}, 4 \mathrm{~mm} \mathrm{Mg-ATP}$, and 0.3 mM Na-GTP; pH 7.2 with KOH. The Tyrode's solution contained the following: $151 \mathrm{~mm} \mathrm{NaCl}, 2 \mathrm{~mm} \mathrm{CaCl}, 10 \mathrm{~mm}$ HEPES, and $13 \mathrm{~mm}$ glucose; $\mathrm{pH} 7.4$ with $\mathrm{NaOH}$. After the whole cell configuration was established, solutions were applied directly to the cell by using an array of quartz fiber flow pipes ( $320 \mu \mathrm{m}$ in internal diameter) containing the test solution and glued on an aluminum rod controlled with a micromanipulator. All experiments were conducted close to a physiological temperature $\left(35 \pm 1^{\circ} \mathrm{C}\right)$. Solutions were heated by using a temperature controller (Warner TC-344B, Warner Instruments).

\section{Quantitative PCR (qPCR)}

DRG (L4) were excised from SCI and sham rats at three months postinjury or postlaminectomy, respectively, and age matched naive rats. RNAs were isolated using the RNeasy mini kit (QIAGEN) according to the manufacturer's instructions and cDNA was generated using the Superscript III First Strand Synthesis system (Thermo Fisher Scientific). qPCR was performed on a StepOne Plus Real Time PCR system (Applied Biosystems) using a Power SYBR green mix (Thermo Fisher Scientific) as previously described (Glaser and Kaczocha, 2010). The following primers were used: $\beta$-actin, forward $5^{\prime}$-GAGGCTCTCTTC CAGCCTTC-3' and reverse 5'-CGGATGTCAACGTCACACTT-3';

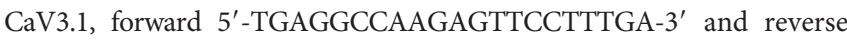
5'-GAAGCCGACTTGCCATTACAG-3'; CaV3.2, forward 5'-ATGT CATCACCATGTCCATGGA- $3^{\prime}$ and reverse $5^{\prime}$-ACGTAGTTGCAGT ACTTGAGG-3'; CaV3.3, forward 5' -CATCCGCACTGTGCGTGT 
CCTG-3' and reverse 5'-CAGCATGG GCAGCGTGTCGAG-3'. Negative controls lacking cDNA were included for all reactions. Amplification levels were determined by using the $\Delta \Delta \mathrm{Ct}$ method with $\beta$-actin serving as the housekeeping gene.

\section{Conditioned place preference (CPP)} paradigm

The CPP paradigm, using analgesics as the conditioning stimuli, is used to measure spontaneous ongoing pain (King et al., 2009; Yang et al., 2014; Griggs et al., 2015). The CPP box (Harvard Apparatus) with automated data collection has three chambers with equal levels of dim illumination: black and white end chambers and a connecting gray chamber. Rats were habituated to the CPP box during the preconditioning time $(30 \mathrm{~min} / \mathrm{d}$ for $4 \mathrm{~d})$ and were allowed to explore the CPP box without restriction. After the preconditioning time, on day 5, each rat was placed in the gray chamber with unrestricted access to all chambers for $15 \mathrm{~min}$, and the time spent in each chamber was measured. The pairing session took place during the next $4 \mathrm{~d}$ (days 6-9). Each morning, the rat was injected with $100 \mu \mathrm{l}$ of vehicle (intraperitoneally) and was confined in the black chamber for $60 \mathrm{~min}$ before returning to its cage. Three hours later, the same rat was injected with $100 \mu \mathrm{l}$ of TTA-P2 $(10 \mathrm{mg} / \mathrm{kg}$, i.p.) and confined to the white chamber for $60 \mathrm{~min}$. On day 10, no drug or vehicle was administered, and each rat was placed in the gray chamber with unrestricted access to all chambers for $15 \mathrm{~min}$. The time spent in each chamber was measured and compared with the time before pairing. Analgesia is associated with the differences in time spent in the drug-paired chamber. Results are reported as difference score measured as the time difference in each chamber before and after the pairing session. Sham animals were included in the study to control for addictive, aversive, or other nonpain related contributions to drug-induced behavioral changes.

\section{Data acquisition and analysis}

Currents and voltages were controlled and sampled using a Digidata 1440A interface and pCLAMP 10.3 software (Molecular Devices). Current or voltage signals were filtered at $10 \mathrm{kHz}(3 \mathrm{~dB}, 4$-pole Bessel $)$ and digitized at $50 \mathrm{kHz}$. Analysis was performed using Clampfit 10.3 and IGOR Pro (version 6.2; WaveMetrics) using DataAccess (Bruxton) to import pCLAMP files into IGOR.

\section{Experimental design and statistical analysis}

Figure 1 shows representative images of the spinal cord. Figure 2 shows a representative record of spontaneous activity from a SCI-nociceptor and the action potential-clamp technique. For the data shown in Figure 3, 12-20 DRGs were recorded for each group from a total of 27 rats, and data were analyzed with one-way ANOVA followed by Tukey's post hoc comparison test. For the data shown in Figure 4A, 72 DRGs were recorded from 19 SCI rats, and 46 DRGs were recorded from 12 sham rats, and data were analyzed with two-way ANOVA followed by Sidak's post hoc comparison. For the data shown in Figure 4B, the charge was measured from the interspike currents recorded from the same DRGs, and data were analyzed with unpaired $t$ test. For the data shown in Figure $4 C$, for each of the $19 \mathrm{SCI}$ rats, the total interspike calcium charge was plotted against the BBB score, and data were analyzed with the Spearman correlation. For data shown in Figure $4 D$, the TTX-sensitive and TTX-resistant sodium current were recorded from 13 DRGs, and the Ih current was recorded from 12 DRGs from a total of six SCI rats, and data were analyzed with one-way ANOVA followed by Tukey's post hoc comparison test. For data shown in Figure $5 B$, the total calcium charge and the T-type calcium charge were measured in 72 DRGs from a total of $19 \mathrm{SCI}$ rats used in Figure 4. For the N-type, P/Q-type, R-type, and L-type calcium charges, 10-13 DRGs were recorded for each group 


\section{A}

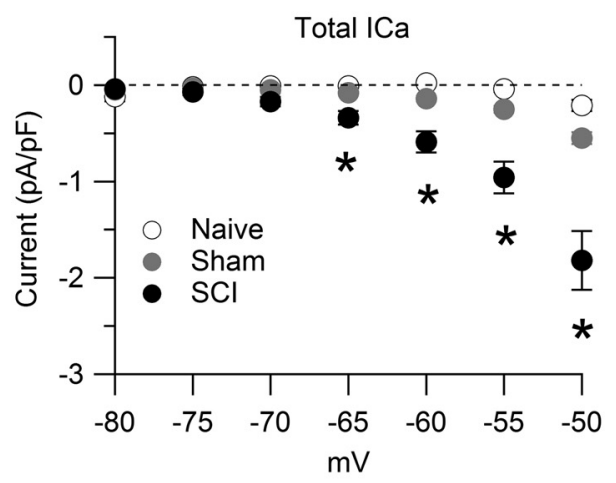

C

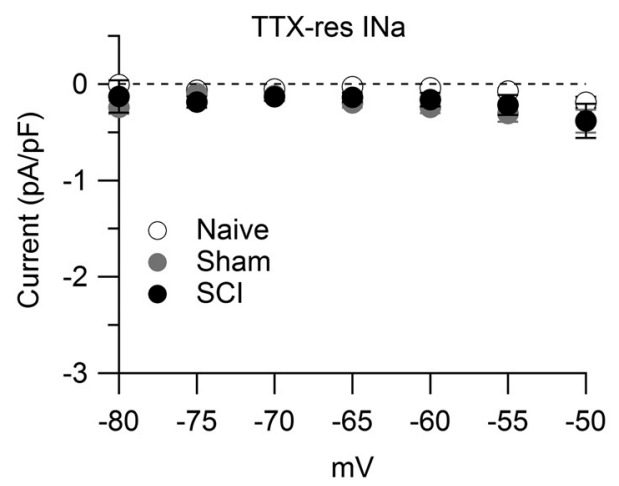

B

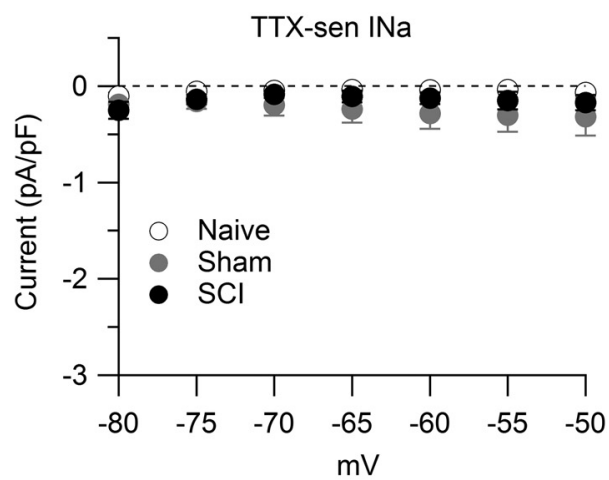

D

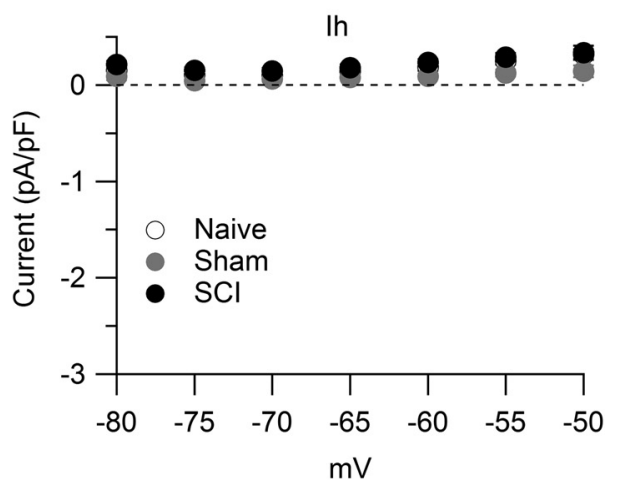

Figure 3. Interspike calcium, sodium, and Ih currents. Interspike currents were measured in SCl-nociceptors and sham-nociceptors isolated at $15 \mathrm{~d}$ postinjury and postlaminectomy, respectively, and in age-matched naive-nociceptors. $\boldsymbol{A}$, Total interspike calcium current isolated as the current sensitive to replacement of $2 \mathrm{~mm} \mathrm{Ca}^{2+}$ with $2 \mathrm{~mm} \mathrm{Co}^{2+}$ in the external solution in naive-nociceptors (white dots, $n=16$ ), sham-nociceptors (gray dots, $n=15$ ), and SCI-nociceptors (black dots, $n=17$ ). $\boldsymbol{B}$, Interspike TTX-sensitive (TTX-sen) sodium current isolated as the current sensitive to $1 \mu \mathrm{m}$ TTX in naive-nociceptors (white dots, $n=13$ ), sham-nociceptors (gray dots, $n=17$ ), and SCI-nociceptors (black dots, $n=18$ ). C, Interspike TTX-resistant (TTX-res) sodium current isolated as the current sensitive to $1 \mu \mathrm{m}$ A803467 applied on top of $1 \mu \mathrm{m}$ TTX in naive-nociceptors (white dots, $n=13$ ), sham-nociceptors (gray dots, $n=17$ ), and SCl-nociceptors (black dots, $n=18$ ). $\boldsymbol{D}$, Interspike Ih current isolated as the current sensitive to $3 \mathrm{~mm} \mathrm{Cs}{ }^{+}$in naive-nociceptors (white dots, $n=12$ ), sham-nociceptors (gray dots, $n=17$ ), and SCI-nociceptors (black dots, $n=20$ ). One-way ANOVA followed by Tukey's post hoc comparison test. $A$, At $-65 \mathrm{mV}$ : sham versus naive, $p=0.69 ; \mathrm{SCl}$ versus naive, ${ }^{*} p<0.05 ; \mathrm{SCl}$ versus sham, ${ }^{*} p<0.05$. At $-50 \mathrm{mV}$ : sham versus naive, $p=0.48$; SCI versus naive, ${ }^{*} p<0.05$; SCI versus sham, ${ }^{*} p<0.05$. Data are reported as mean \pm SEM.

from a total of seven SCI rats. Data were analyzed with one-way ANOVA followed by Tuckey's post hoc comparison test. For data shown in Figure $5 C$, the total calcium charge and the T-type calcium charge were measured in $46 \mathrm{DRG}$ from a total of 12 sham rats. For the Ntype, P/Q-type, R-type, and L-type calcium charges, 9-12 DRGs were recorded for each group from a total of eight SCI rats. Data were analyzed with one-way ANOVA followed by Tuckey's post hoc comparison test. For data shown in Figure 6B, 13 DRGs were recorded from five SCI rats, and data were analyzed with paired $t$ test. For data shown in Figure 6G, 19 DRGs were recorded from five SCI rats, and data were analyzed with two-way ANOVA followed by Sidak's post hoc comparison. For data shown in Figure 6H, 15 DRGs were recorded from four sham rats, and data were analyzed with two-way ANOVA followed by Sidak's post hoc comparison. For data shown in Figure $7 A, B$, a total of 13 SCI rats were used. For data shown in Figure $7 C$, a total of six sham rats were used. Data were analyzed with paired $t$ test. For data shown in Figure $7 D$, the total calcium charge was measured in 21 DRGs from seven SCI rats, and data were analyzed with unpaired $t$ test. For data shown in Figure $7 E$, the T-type calcium charge was measured in $24 \mathrm{DRG}$ from six SCI rats, and data were analyzed with unpaired $t$ test. For data shown in Table 1, the L4 DRG was taken out from three SCI rats, three sham rats, and three naive rats. Experiments were run in triplicates. Data were analyzed with one-way ANOVA followed by Tuckey's post hoc comparison test. Differences were considered significant at ${ }^{*} p<0.05$. Data are reported as mean \pm SEM or mean \pm
$\mathrm{SD}$ as stated in the figure legend. Statistical analysis was performed by using Prism 7 software (GraphPad).

\section{Results}

\section{Histologic examination of the spinal cord}

At three months postinjury, visual inspection of the spinal cord showed a significant reduction in the diameter of the spinal cord at the site of injury $(\mathrm{T} 10, \sim 2700 \mu \mathrm{m})$ relative to rostral and caudal sites (T8 and L1, $\sim 5500 \mu \mathrm{m}$ ). Sites rostral and caudal to the impact zone had a distinct off-white shade, while the impact site was gray like in tone. Histologic examination of the spinal cord showed a drastic reorganization of the gray and white matter, reduced myelination, and formation of large cystic cavities at the site of injury (Fig. 1).

\section{Interspike currents}

We employed the action potential-clamp technique (Raman and Bean, 1999; Puopolo et al., 2007) to directly identify and measure the contribution of calcium, sodium, and hyperpolarization-activated cyclic nucleotide-gated $(\mathrm{HCN})$ channels active at subthreshold voltages during the interspike interval in nociceptors. Action potentials were first recorded in current clamp from a spontaneously active SCI-nociceptor (Fig. 2A) and then used as 
3 months post-injury

A

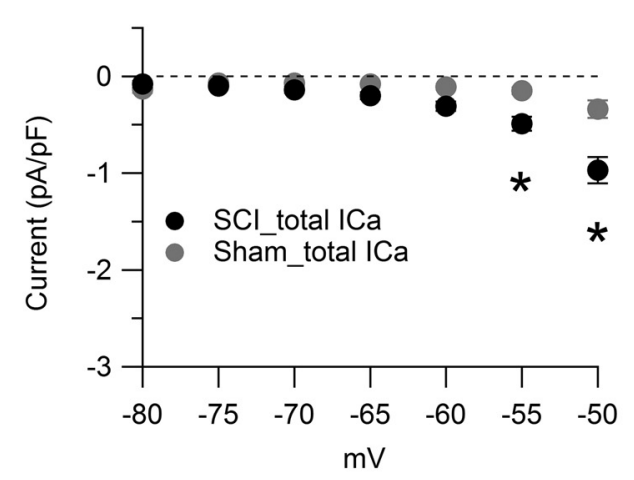

C

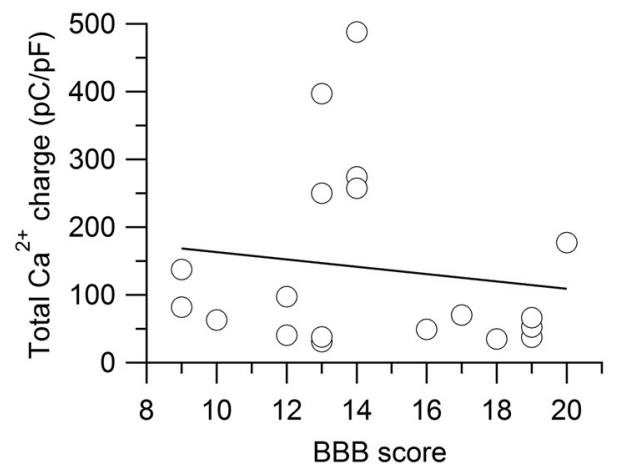

B

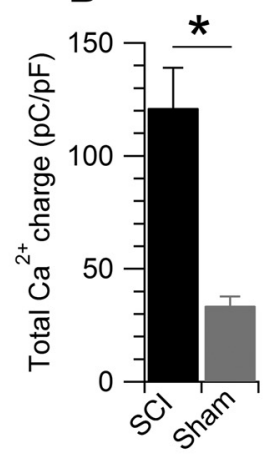

D

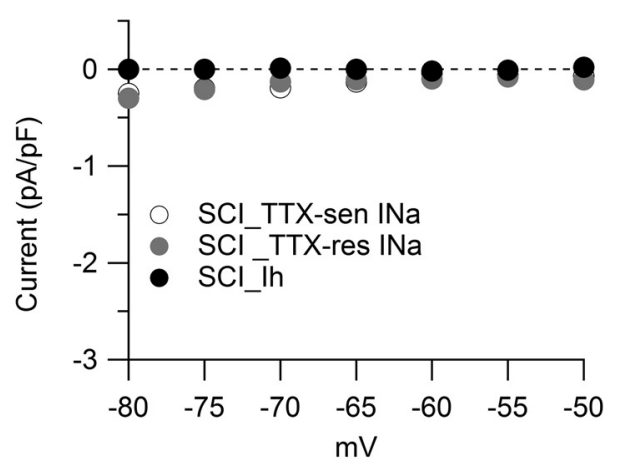

Figure 4. Interspike calcium current at three months postinjury. Interspike currents were measured in SCl-nociceptors and sham-nociceptors isolated at three months postinjury and postlaminectomy, respectively. $A$, Total interspike calcium current isolated as the current sensitive to replacement of $2 \mathrm{~mm} \mathrm{Ca}{ }^{2+}$ with $2 \mathrm{~mm} \mathrm{C0^{2+ }}$ in the external solution in SCl-nociceptors (black dots, $n=72$ ) and sham-nociceptors (gray dots, $n=46$ ). Two-way ANOVA followed by Sidak's post hoc comparison, ${ }^{*} p<0.05$. $\boldsymbol{B}$, Total interspike calcium charge measured by integrating the currents shown in $A$ from the afterhyperpolarization of the first action potential $(-80 \mathrm{mV})$ to the time where the voltage reached $-50 \mathrm{mV}$ before the second action potential in SCl-nociceptors (black bar, $121.3 \pm 17.7 \mathrm{pC} / \mathrm{pF}, n=72$ ) and sham-nociceptors (gray bar, $33.7 \pm 3.9 \mathrm{pC} / \mathrm{pF}, n=46$ ). Unpaired $t$ test, ${ }^{*} p<0.05$. C, Correlation between the total interspike calcium charge and the $\mathrm{BBB}$ score for the $\mathrm{SCl}$ rats ( $n=19$ rats) shown in panel $\boldsymbol{B}$. Spearman correlation, $p=0.62, r=-0.123$. $\boldsymbol{D}$, Interspike TTX-sensitive (TTX-sen) sodium current isolated as the current sensitive to $1 \mu \mathrm{m}$ TTX in SCI-nociceptors (white dots, $n=13$ ). Interspike TTX-resistant (TTX-res) sodium current isolated as the current sensitive to $1 \mu \mathrm{m}$ A803467 applied on top of $1 \mu \mathrm{m}$ TTX in SCI-nociceptors (gray dots, $n=13$ ). Interspike $\mathrm{lh}$ current isolated as the current sensitive to $3 \mathrm{~mm} \mathrm{Cs}{ }^{+}$in SCI-nociceptors (black dots, $\left.n=12\right)$. One-way ANOVA followed by Tukey's post hoc comparison test. Data are reported as mean \pm SEM.

voltage command in voltage clamp (Fig. 2D). The initial sets of experiments were conducted in SCI-nociceptors and sham-nociceptors isolated at two weeks postinjury and postlaminectomy, respectively, and in age-matched naive-nociceptors. Spontaneous action potentials showed a characteristic shoulder during the repolarization phase (Fig. $2 B)$ and a long duration $(\sim 4.5 \mathrm{~ms}$, measured at half-maximal amplitude; Fig. $2 C$ ) typical of nociceptors (Cardenas et al., 1995, 1997; Petruska et al., 2000; Blair and Bean, 2002). In SCI-nociceptors, the total interspike calcium current (isolated as the current sensitive to replacement of $2 \mathrm{mM} \mathrm{Ca}^{2+}$ with $2 \mathrm{mM} \mathrm{Co}^{2+}$ in the external solution) was 4to 5-fold larger than the TTX-sensitive sodium current, the TTX-resistant sodium current, and the Ih current (Fig. 2D), suggesting an increased activity of calcium channels induced by the injury. To determine whether the increased activity of calcium channels in SCI-nociceptors during the interspike interval was induced by the contusion of the spinal cord or it was a consequence of the surgery, we then compared the size of the interspike calcium, sodium, and Ih current between SCI, sham, and age-matched naive nociceptors. Ionic currents through calcium, sodium, and HCN channels active at subthreshold voltages were measured during the interspike interval from the afterhyperpolarization of the first action potential to $-50 \mathrm{mV}$ before the threshold of the second action potential (Fig. 2D). While the size of the total calcium current during the interspike interval was 4- to 5-fold larger in SCI-nociceptors as compared with sham-nociceptors and naive-nociceptors (Fig. $3 A$ ), the size of the TTX-sensitive (Fig. 3B), the TTX-resistant (Fig. 3C), and the Ih current (Fig. 3D) was unchanged, pointing to a selective increase in the activity of calcium channels induced by the injury. Next, we tested whether the increased activity of calcium channels induced by the injury was limited to a short period following the injury or persisted over time. To this purpose, we measured the size of the total calcium current during the interspike interval in SCI-nociceptors and sham-nociceptors isolated at three months postinjury and postlaminectomy, respectively. Similar to the results at two weeks postinjury, the size of the total calcium current during the interspike interval was much larger in SCI-nociceptors as compared with shamnociceptors at three months postinjury (Fig. 4A), suggesting a long-lasting increase in the activity of calcium channels induced by the injury. With a mild to moderate impact of the spinal cord (150 kilodynes), rats partially recover the motor function as suggested by the recovery in the BBB score (Basso et al., $1995,1996)$ from zero (at days $0-1)$ to $14 \pm 3(n=19$ rats, at three months postinjury). However, there was no apparent 

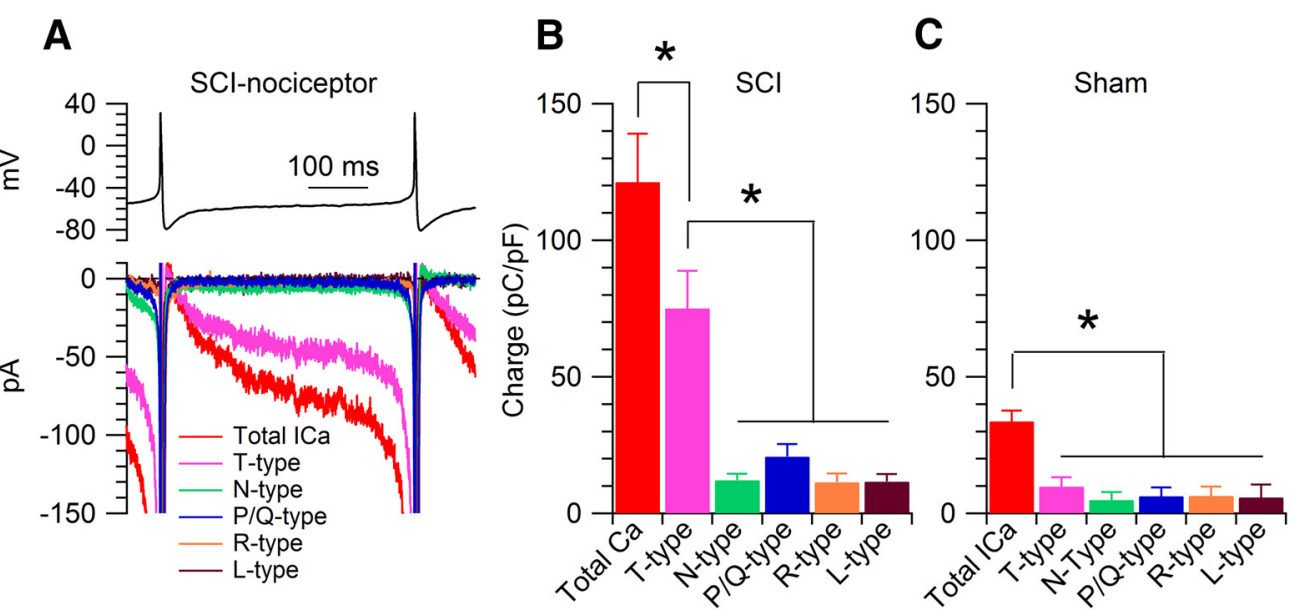

Figure 5. Pharmacology of interspike calcium current. $\boldsymbol{A}$, Recordings from a SCl-nociceptor isolated at three months postinjury. Top panel, Action potentials recorded in current clamp from a spontaneously active SCI-nociceptor were used as voltage command in voltage clamp. Bottom panel, Representative interspike currents isolated by subtracting traces (average of three consecutive traces) before and after application of a specific blocker. Total calcium current (red trace) isolated as the current sensitive to replacement of $2 \mathrm{~mm} C \mathrm{a}^{2+}$ with $2 \mathrm{~mm}$ $\mathrm{Co}^{2+}$ in the external solution; T-type calcium current (magenta trace) isolated as the current sensitive to $1 \mu \mathrm{m} \mathrm{TTA-P2;} \mathrm{N-type} \mathrm{calcium} \mathrm{current} \mathrm{(green} \mathrm{trace)} \mathrm{isolated} \mathrm{as} \mathrm{the} \mathrm{current} \mathrm{sen-}$ sitive to $2 \mu \mathrm{m} \omega$-conotoxin GVIA; P/Q-type calcium current (blue trace) isolated as the current sensitive to $500 \mathrm{~nm} \omega$-agatoxin IVA; R-type calcium current (orange trace) isolated as the current sensitive to $200 \mathrm{nM}$ SNX-482; L-type calcium current (brown trace) isolated as the current sensitive to $2 \mu \mathrm{m}$ nimodipine applied on top of $2 \mu \mathrm{m} \omega$-conotoxin MVIIC and $200 \mathrm{~nm}$ SNX-482. B, Interspike calcium charge in SCI-nociceptors. The charge was measured by integrating the interspike calcium currents from the afterhyperpolarization of the first action potential $(-80 \mathrm{mV})$ to the time where the voltage reached $-50 \mathrm{mV}$ before the threshold for the second action potential. Total calcium charge (red bar, $121.3 \pm 17.7 \mathrm{pC} / \mathrm{pF}$, $n=72)$; T-type calcium charge (magenta bar, $75.1 \pm 13.8 \mathrm{pC} / \mathrm{pF}, n=72$ ); N-type calcium charge (green bar, $12.1 \pm 2.4 \mathrm{pC} / \mathrm{pF}, n=13$ ); P/Q-type calcium charge (blue bar, $20.8 \pm 4.5$ $\mathrm{pC} / \mathrm{pF}, n=11$ ); R-type calcium charge (orange bar, $11.4 \pm 3.2 \mathrm{pC} / \mathrm{pF}, n=10)$ ); L-type calcium charge (brown bar, $11.6 \pm 2.8 \mathrm{pC} / \mathrm{pF}, n=9$ ). One-way ANOVA followed by Tukey's post hoc comparison test, ${ }^{*} p<0.05$. C, Interspike calcium charge in sham-nociceptors. Total calcium charge (red bar, $33.7 \pm 3.9 \mathrm{pC} / \mathrm{pF}, n=46$ ); T-type calcium charge (magenta bar, $9.8 \pm 3.4 \mathrm{pC} / \mathrm{pF}, n=46$ ); N-type calcium charge (green bar, $4.9 \pm 2.8 \mathrm{pC} / \mathrm{pF}, n=12$ ); P/Q-type calcium charge (blue bar, $6.3 \pm 3.2 \mathrm{pC} / \mathrm{pF}, n=12$ ); R-type calcium charge (orange bar, $6.4 \pm 3.4 \mathrm{pC} / \mathrm{pF}, n=9$ ); L-type calcium charge (brown bar, $5.8 \pm 4.7 \mathrm{pC} / \mathrm{pF}, n=10$ ). One-way ANOVA followed by Tukey's post hoc comparison test, ${ }^{*} p<0.05$. Data are reported as mean \pm SEM.

correlation between the $\mathrm{BBB}$ score and the size of the total interspike calcium charge (Fig. 4C), suggesting that the size of the interspike calcium current in SCI-nociceptors is not affected by the recovery of the motor function. In contrast, the TTX-sensitive, the TTX-resistant, and the Ih current recorded in SCI-nociceptors at three months postinjury (Fig. 4D) were of similar size as those recorded in naive-nociceptors, sham-nociceptors, and SCI-nociceptors at two weeks postinjury (for comparison, see Fig. 3). Taken together, the data suggest a major contribution of calcium channels to the injury-induced hyperexcitability of nociceptors, with little or minimal contribution from TTX-sensitive and TTX-resistant sodium channels, and HCN channels.

The next step was to determine which type of calcium channel(s) sustain the calcium current during the interspike interval in SCI-nociceptors. For this purpose, we determined the sensitivity of the interspike calcium current to specific calcium channels blockers (Fig. 5A) in SCI-nociceptors isolated at three months postinjury. As shown in Figure $5 B$, the interspike calcium charge sensitive to $1 \mu \mathrm{M}$ TTA-P2, a blocker of T-type calcium channels (Shipe et al., 2008; Choe et al., 2011), accounts for $\sim 65-70 \%$ of the total interspike calcium charge in SCI-nociceptors. The remaining interspike calcium current is carried by a combination of $\mathrm{N}$-type $(\sim 10 \%)$, P/Q-type ( $\sim 17 \%)$, R-type $(\sim 9 \%)$, and L-type $(\sim 10 \%)$ calcium channels, as determined by sensitivity to $2 \mu \mathrm{M} \omega$-conotoxin GVIA, 500 nм $\omega$-agatoxin IVA, $200 \mathrm{~nm}$ SNX-482, and $2 \mu \mathrm{m}$ nimodipine, respectively (Mintz et al., 1992). In contrast, in sham-nociceptors (Fig. $5 C$ ) the interspike calcium charge sensitive to $1 \mu \mathrm{M}$ TTA-P2 is much smaller and accounts for $\sim 30 \%$ of the total interspike calcium charge, with similar contribution from $\mathrm{N}$ - type, P/Q-type, R-type, and L-type calcium channels. Taken together, our data suggest that the increased activity of T-type calcium channels induced by the injury plays a primary role in driving SCI-nociceptors to a hyperexcitable state. To further test this possibility, we determined the effect of TTA-P2 on the spontaneous firing and the frequency-current (f-I) relationship in SCI-nociceptors during current-clamp recordings. As shown in Figure $6 A, B$, in spontaneously active SCI-nociceptors $1 \mu \mathrm{M}$ TTA-P2 reduced the firing frequency from $1.8 \pm 0.3$ to $0.3 \pm 0.1 \mathrm{~Hz}(n=13)$. Similarly, inhibition of T-type calcium channels with $1 \mu \mathrm{M}$ TTA-P2 reduced the f-I relationship in SCI-nociceptors (Fig. 6G). In contrast, $1 \mu \mathrm{M}$ TTA-P2 had little or minimal effect on the f-I relationship in sham-nociceptors (Fig. $6 H$ ), confirming that the increased activity of T-type calcium channels plays a major role in driving SCI-nociceptors to a hyperexcitable state following the injury.

Previous reports have shown that in rats subjected to SCI there is a strong relationship between the severity of pain following the injury and the incidence of spontaneous activity of SCInociceptors (Bedi et al., 2010). This prompted us to test whether there was also a relationship between chronic neuropathic pain following the injury and the increased activity of T-type calcium channels during the interspike interval. The CPP paradigm has been employed as an approach to unmask spontaneous ongoing pain in different rodent models of neuropathic pain such as the spinal nerve ligation (King et al., 2009), the spare nerve injury (SNI; Griggs et al., 2015), the tibial nerve injury (Pan et al., 2016), and SCI (Davoody et al., 2011; Yang et al., 2014; Wu et al., 2017). Rats subjected to SCI were first tested with the CPP paradigm and subsequently DRGs were isolated from L3, L4, and L5 DRG from the same animals for in vitro electrophysiological 


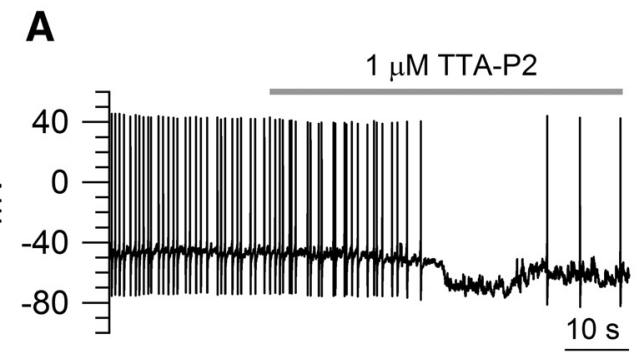

B
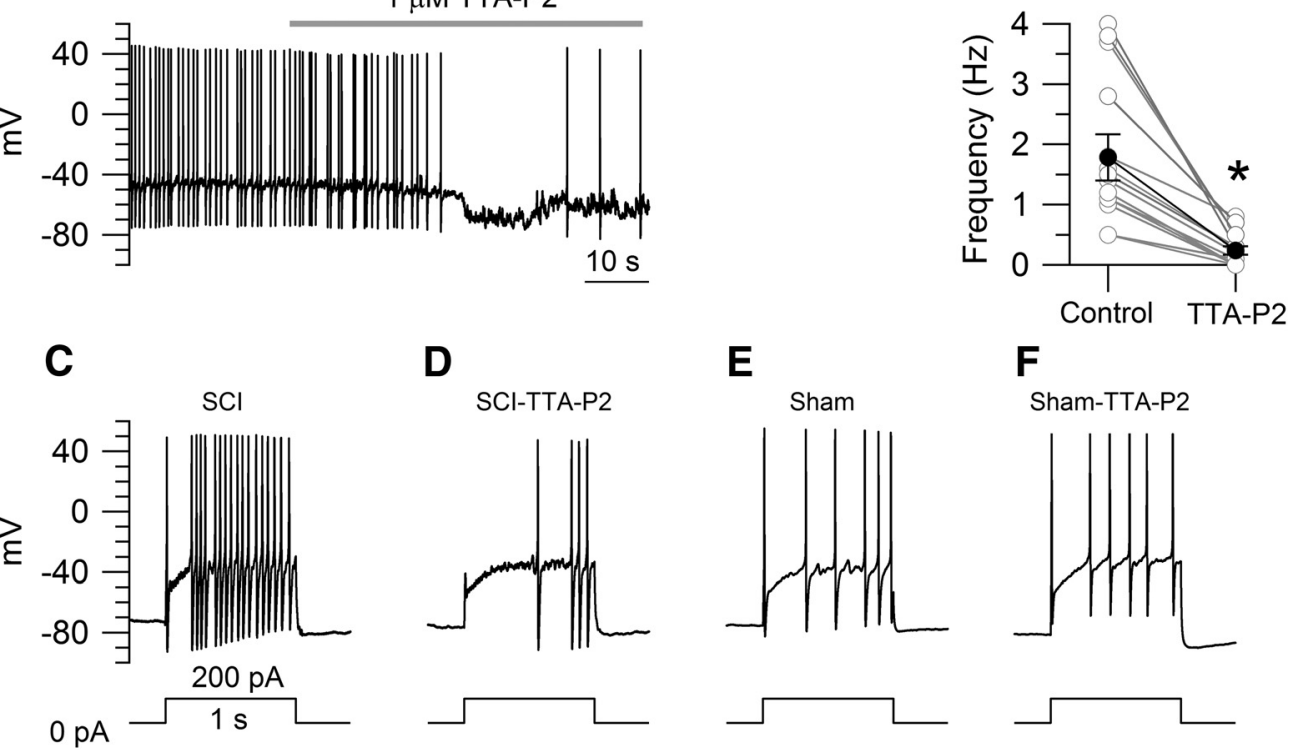

D SCI-TTA-P2

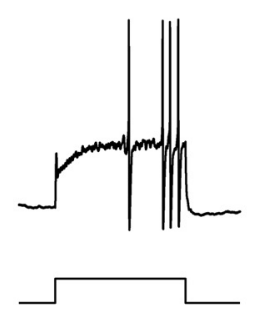

$\mathbf{F}$

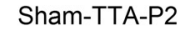

E

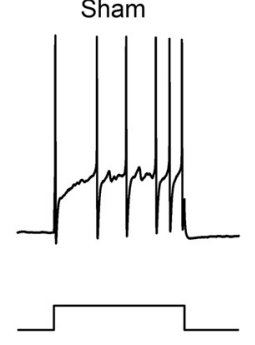

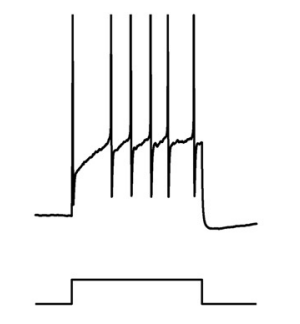

\section{G}

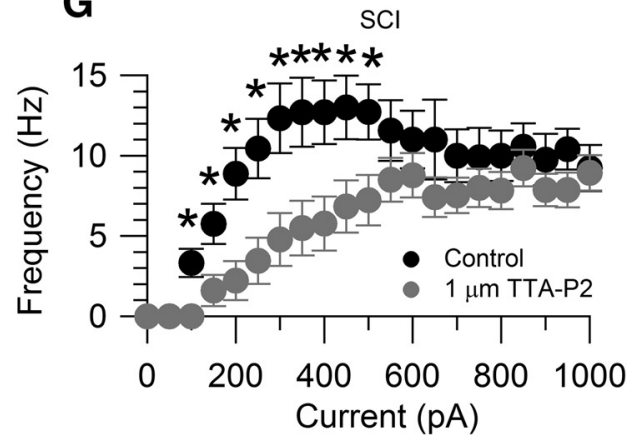

H

Sham

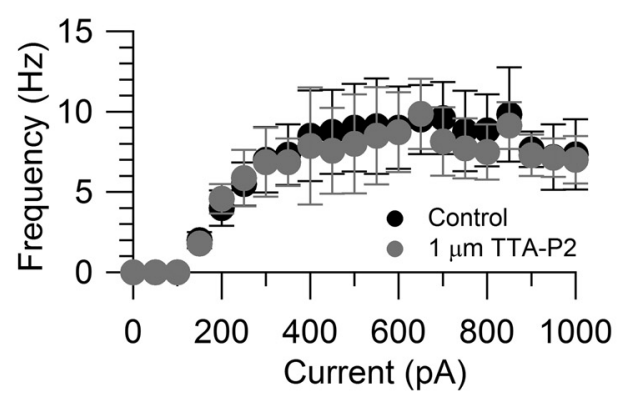

Figure 6. Effects of TTA-P2 on the increased excitability of SCI-nociceptors. A, Spontaneous activity in a SCI-nociceptor isolated at three months postinjury. The firing frequency was reduced from $1.4 \mathrm{~Hz}$ (in control) to $0.2 \mathrm{~Hz}$ in the presence of $1 \mu \mathrm{m} \mathrm{TTA}-\mathrm{P} 2$. $\boldsymbol{B}$, In collected results, the firing frequency was reduced from $1.8 \pm 0.3 \mathrm{~Hz}$ (in control) to $0.3 \pm 0.1 \mathrm{~Hz}$ in the presence of 1 $\mu \mathrm{m}$ TTA-P2 $(n=13)$. Paired $t$ test, ${ }^{*} p<0.05$. Current-clamp recordings in a SCl-nociceptor isolated at three months postinjury showing the evoked firing in response to $200 \mathrm{pA}$ of current injection in control $(\boldsymbol{C})$ and in the presence of $1 \mu \mathrm{m}$ TTA-P2 $(\boldsymbol{D})$. Current-clamp recordings in a sham-nociceptor isolated at three months postlaminectomy showing the evoked firing in response to $200 \mathrm{pA}$ of current injection in control $(\boldsymbol{E})$ and in the presence of $1 \mu \mathrm{m} \mathrm{TTA-P2}(\boldsymbol{F})$. G, f-I relationship in response to current injections from 0 to $1000 \mathrm{pA}$ (50-pA increment) in SCl-nociceptors in control (black dots) and in the presence of $1 \mu \mathrm{m}$ TTA-P2 (gray dots, $n=19$ ). $\boldsymbol{H}, \mathrm{f}-\mathrm{I}$ relationship in response to current injections in sham-nociceptors in control (black dots) and in the presence of $1 \mu \mathrm{m}$ TTA-P2 (gray dots, $n=15$ ). The $\mathrm{f}-\mathrm{I}$ curves were generated from the same neurons before and after TTA-P2 application. The $\mathrm{f}-\mathrm{I}$ curve was first generated in control. Then, the same cell was held at the resting potential and continuously perfused with $1 \mu \mathrm{m}$ TTA-P2 for 3 min before a second f-I curve was generated in the presence of $1 \mu \mathrm{m}$ TTA-P2. G, $\boldsymbol{H}$, Two-way ANOVA followed by Sidak's post hoc comparison, ${ }^{*} p<0.05$. Data are reported as mean \pm SEM.

recordings. Of the $13 \mathrm{SCI}$ rats tested with the CPP paradigm, seven rats showed preference for the TTA-P2 paired chamber and were identified as responders (Fig. $7 \mathrm{~A}$ ), while the remaining six SCI rats had no preference for the TTA-P2 paired chamber and were identified as non-responders (Fig. $7 B$ ). Importantly, TTA-P2 did not induce CPP in sham rats (Fig. 7C), confirming that the effects of TTA-P2 were pain specific. In SCI-nociceptors isolated from responders, the total interspike calcium charge and the interspike T-type calcium charge were significantly larger than those recorded from SCI-nociceptors isolated from nonresponders (Fig. $7 D, E$ ). Taken together, these data strongly suggest that the increased activity of T-type calcium channels induced by the injury plays a major role in driving SCI-nociceptors to a hyperexcitable state and contributes to chronic neuropathic pain following SCI.

DRGs express all three isoforms of T-type calcium channels (CaV3.1, CaV3.2, and CaV3.3; Talley et al., 1999; Shin et al., 2003). To determine which CaV3 isoform(s) contributes to the increased activity of T-type calcium channels during the interspike interval, we employed qPCR to profile the expression of CaV3.1, CaV3.2, and CaV3.3 in DRGs isolated from SCI and sham rats at three months postinjury or postlaminectomy, respectively, and age-matched naive rats. Our results (Table 1) show that the expression levels of the three $\mathrm{CaV} 3$ isoforms is similar between SCI, sham, and naive DRGs, suggesting that the increased activity of T-type calcium channels in SCI-nociceptors is not simply caused by upregulation of the mRNA. Future experiments are required to determine the underlying mechanism(s) responsible for the increased activity of T-type calcium channels induced by SCI.

\section{Discussion}

The data presented here provide strong evidence that the increased activity of T-type calcium channels induced by the 


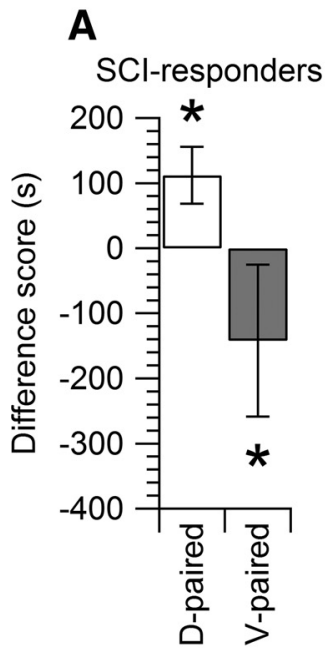

D

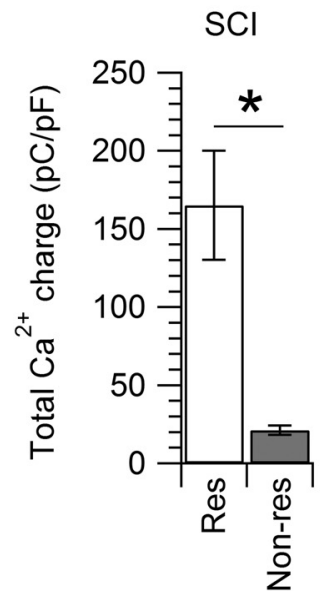

B

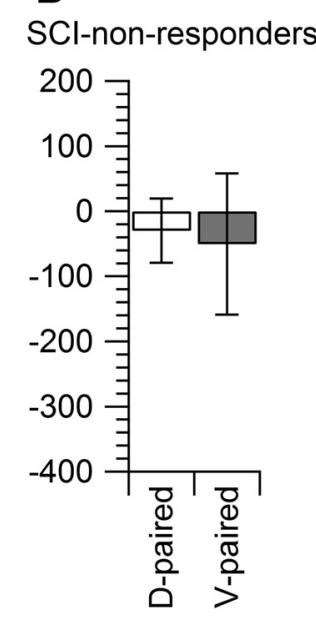

E

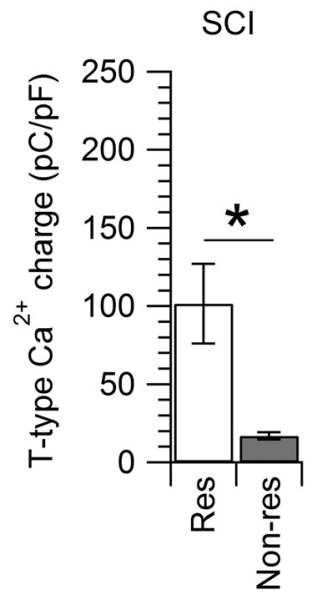

C

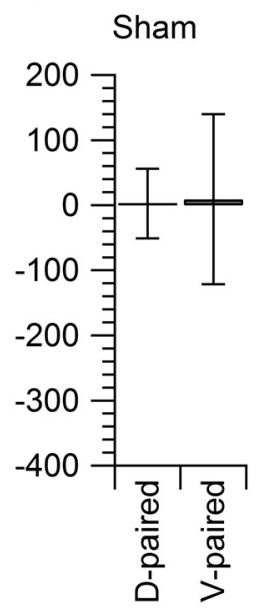

Figure 7. Interspike calcium current and spontaneous pain. SCl and sham rats were subjected to the CPP paradigm by using a CPP box with three chambers. The white chamber was paired with TTA-P2 $(10 \mathrm{mg} / \mathrm{kg}$, i.p.), while the black chamber was paired with vehicle. $\boldsymbol{A}$, of the $13 \mathrm{SCl}$ rats tested, seven rats (identified as responders) showed an increase in the difference score of $+112 \pm 43 \mathrm{~s}$ for the drug paired chamber (D-paired, white bar) and a decrease of $-142 \pm 116 \mathrm{~s}$ in the vehicle paired chamber (V-paired, gray bar). Paired $t$ test, ${ }^{*} p<0.05 . B, 0$ the $13 \mathrm{SCl}$ rats tested, six rats (identified as non-responders) showed a decrease of $-30 \pm 49 \mathrm{~s}$ in the D-paired chamber (white bar) and a decrease of $-50 \pm 108 \mathrm{~s}$ in the V-paired chamber (gray bar). $\boldsymbol{C}$, Sham rats $(n=6)$ showed an increase of $3 \pm 53 \mathrm{~s}$ in the D-paired chamber (white bar) and an increase of $9 \pm 130 \mathrm{~s}$ in the V-paired chamber (gray bar). Data are reported as mean \pm SD. $D$, Comparison of the total interspike $\mathrm{Ca}^{2+}$ charge (measured by integrating the total calcium current from -80 to $-50 \mathrm{mV}$ ) in SCl-nociceptors from responders ( $165 \pm 35 \mathrm{pC} / \mathrm{pF}, n=21$, res, white bar) versus non-responders ( $21 \pm 3 \mathrm{pC} / \mathrm{pF}, n=48$, non-res, gray bar). Unpaired $t$ test, ${ }^{*} p<0.05$. $\boldsymbol{E}$, Comparison of the interspike T-type calcium charge in $\mathrm{SCl}$-nociceptors from responders (101 $\pm 25 \mathrm{pC} / \mathrm{pF}, n=24$, res, white bar) versus non-responders (17 $\pm 2 \mathrm{pC} / \mathrm{pF}$, $n=46$, non-res, gray bar). Unpaired $t$ test, ${ }^{*} p<0.05$.

Table 1. qPCR: average $\mathrm{CT}$ value \pm SEM

\begin{tabular}{lllll}
\hline & CaV3.1 & CaV3.2 & CaV3.3 & $\beta$-Actin \\
\hline Naive & $34.1 \pm 0.6$ & $30.8 \pm 1.0$ & $35.1 \pm 0.7$ & $23.2 \pm 0.7$ \\
Sham & $34.6 \pm 1.0$ & $30.2 \pm 0.7$ & $34.4 \pm 0.9$ & $22.8 \pm 0.6$ \\
SCl & $34.5 \pm 1.2$ & $29.9 \pm 0.7$ & $34.8 \pm 0.4$ & $22.8 \pm 0.9$ \\
\hline
\end{tabular}

One-way ANOVA followed by Tuckey's post hoc comparison test.

injury plays a major role in driving SCI-nociceptors to a hyperexcitable state. Only small DRGs (diameter $<27 \mu \mathrm{m}$ and cell capacitance of $36 \pm 6 \mathrm{pF}, n=418)$ sensitive to capsaicin $(69 \%$ of those tested) were included in the study, suggestive of putative nociceptors (Cardenas et al., 1995; Caterina et al., 1997; Petruska et al., 2000; Ho and O’Leary, 2011).

A hyperexcitable state of nociceptors has been reported in different animal models of neuropathic pain (Meyer et al., 1985; Michaelis et al., 1995; Ali et al., 1999; Gorodetskaya et al., 2003; Djouhri et al., 2006; Jagodic et al., 2007, 2008; Dib-Hajj et al., 2010; Xu and Brennan, 2010; Waxman and Zamponi, 2014). SCInociceptors show a similar increase in hyperexcitability and spontaneous activity (Carlton et al., 2009; Bedi et al., 2010; Wu et al., 2013; Yang et al., 2014; Bavencoffe et al., 2016; Odem et al., 2018), and behavioral experiments in vivo combined with electrophysiology have shown that there is a strong link between the severity of pain and the incidence of spontaneous activity of SCI-nociceptors (Bedi et al., 2010). Taken together with our data, these studies point to the increased excitability and spontaneous activity of SCI-nociceptors as a possible underlying mechanism for the development of chronic neuropathic pain following SCI (Walters, 2012).

The spontaneous activity of SCInociceptors reported here and in previous studies (Bedi et al., 2010; Yang et al., 2014; Bavencoffe et al., 2016; Odem et al., 2018) resembles to some extent the pacemaker like activity found in many central neurons (Raman and Bean, 1999; Taddese and Bean, 2002; Do and Bean, 2003; Puopolo et al., 2005, 2007; Khaliq and Bean, 2010), in which the action potential-clamp technique was successfully employed to uncover the underlying ionic mechanisms responsible for driving their spontaneous activity. Pharmacological data have shown that sodium channels active at subthreshold voltages play a primary role in driving the interspike depolarization necessary to generate the spontaneous activity of many central neurons (Raman and Bean, 1999; Taddese and Bean, 2002; Do and Bean, 2003; Puopolo et al., 2005, 2007; Khaliq and Bean, 2010), although calcium channels may provide an additional contribution (Puopolo et al., 2005, 2007). Here, we employed the action potential-clamp technique in nociceptors to directly link current-clamp and voltage-clamp experiments in SCI-nociceptors, allowing the identification of the key ion channels responsible for driving SCI-nociceptors to a hyperexcitable state and for promoting their spontaneous activity. Surprisingly, our direct approach showed that the increased activity of T-type calcium channels contributes the bulk $(\sim 65-70 \%)$ of the inward current active at subthreshold voltages during the interspike interval, with minimal contribution of TTX-sensitive and TTXresistant sodium channels $(\sim 10-15 \%)$ and $\mathrm{HCN}$ channels, pointing to the increased activity of T-type calcium channels 
induced by the injury as a major contributor for driving SCInociceptors to a hyperexcitable state. This conclusion is further supported by the finding that the relative contribution of $\mathrm{T}$ type calcium channels to the total interspike calcium current was twice as large in SCI-nociceptors when compared with sham-nociceptors, while the relative contribution of N-type, P/Q-type, R-type, and L-type calcium channels during the interspike interval remained similar between SCI-nociceptors and sham-nociceptors.

By using a similar model of SCI in rat, a recent study found that the increased excitability of SCI-nociceptors was restricted mainly to a subpopulation of nonaccomodating nociceptors (which respond with repetitive firing in response to a suprathreshold depolarizing current injection) in contrast to rapidly accommodating nociceptors (which respond with one single action potential; Odem et al., 2018). In agreement with this study, our results in current clamp showed a similar increase in the excitability of nonaccomodating SCI-nociceptors when compared with sham-nociceptors. Importantly, we found that TTA-P2 (a blocker of T-type calcium channels; Choe et al., 2011) was able to rescue the hyperexcitability of SCI-nociceptors, consistent with the conclusion that the increased activity of T-type calcium channels plays a major role in driving SCI-nociceptors to a hyperexcitable state and for triggering their spontaneous activity. The increased activity of T-type calcium channels in SCI-nociceptors was present from two weeks up to three months postinjury, a time when rats subjected to SCI develop clear signs of thermal and mechanical hypersensitivity and spontaneous pain (Bedi et al., 2010; Yang et al., 2014), pointing to a long-lasting increase in the activity of T-type calcium channels induced by the injury as a possible underlying mechanism responsible for the development of chronic neuropathic pain following SCI. This conclusion is further supported by our combined approach in which behavioral pharmacology in vivo with the CPP paradigm (used to unmask spontaneous pain; King et al., 2009) was combined with electrophysiology in vitro in DRGs isolated from the same animals. In nociceptors isolated from SCI rats that showed CPP in response to TTA-P2 the size of the interspike Ttype calcium current was $\sim 6$ fold higher than that recorded in nociceptors isolated from SCI rats that showed no CPP (Fig. 7). Although we may speculate that the induction of CPP in response to TTA-P2 may suggest the presence of spontaneous pain in SCI rats identified as responders (Fig. 7), a question still remains of whether rats that do not show CPP in response to TTA-P2 (non-responders) may still experience pain that is insensitive to TTA-P2. Future studies are necessary in which known analgesics will be tested in parallel with TTA-P2 to confirm the presence or absence of pain in non-responders.

T-type calcium channels are expressed both in the cell body (Carbone and Lux, 1984; Cardenas et al., 1995; Talley et al., 1999; Todorovic et al., 2001; Nelson et al., 2005; Todorovic and Jevtovic-Todorovic, 2006; Coste et al., 2007; Rose et al., 2013; Watanabe et al., 2015; Rzhepetskyy et al., 2016; Candelas et al., 2019) and peripheral and central terminals (Jacus et al., 2012; Rose et al., 2013) of sensory neurons, and contribute to the intrinsic excitability (White et al., 1989; Perez-Reyes, 2003; Jagodic et al., 2007) and neurotransmitter release (Jacus et al., 2012; Todorovic and Jevtovic-Todorovic, 2013) of nociceptors. Although our study was limited to the cell body of nociceptors, it is reasonable to hypothesize that the increased activity of T-type calcium channels in SCI-nociceptors may contribute to amplify pain signals also in the dorsal horn of the spinal cord (DHSC) by either increasing the excitability and firing of nociceptors, as suggested by or data in current clamp, or by increasing the probability of neurotransmitter release at presynaptic sites, or by both.

The mammalian genome encodes three different isoforms of T-type calcium channels (CaV3.1, CaV3.2, and CaV3.3; Simms and Zamponi, 2014). All three isoforms are expressed in the peripheral nervous system (Talley et al., 1999; Shin et al., 2003), and $\mathrm{CaV} 3.2$ is the predominant isoform found in the spinal cord and primary sensory neurons (Todorovic and JevtovicTodorovic, 2006; Watanabe et al., 2015; Rzhepetskyy et al., 2016; Candelas et al., 2019). Abundant data support the contribution of T-type calcium channels in the development of chronic neuropathic pain. Reduced neuropathic pain states have been reported in CaV3.1 knock-out mice ( $\mathrm{Na}$ et al., 2008; Choi et al., 2016). CaV3.2 has been shown to play a role in the development of neuropathic pain in the SNI model (Chen et al., 2018; Kang et al., 2018), the CCI model (Bourinet et al., 2005; Jagodic et al., 2008), chemotherapy-induced peripheral neuropathy (Tomita et al., 2019), the spinal nerve injury model (Yue et al., 2013), and diabetic peripheral neuropathy (Messinger et al., 2009; Obradovic et al., 2014; Todorovic and Jevtovic-Todorovic, 2014). Increased levels of mRNA for the CaV3.3 isoform (Wen et al., 2010) and attenuated pain by intrathecal injection of antisense (AS) oligonucleotides (ODNs) for CaV3.3 have been reported in the chronic compression of DRG (CCD) in rat (Wen et al., 2006). Interestingly, the expression of the three $\mathrm{CaV} 3$ isoforms did not change between SCI, sham, and naive DRGs (Table 1). This raises the possibility that the increased activity of T-type calcium channels following SCI could be sustained by either increased membrane expression (Joksimovic et al., 2018) or by post-translational modifications of the channels (Zhang et al., 2013; Snutch and Zamponi, 2018; Wang et al., 2019; Weiss and Zamponi, 2019), or by both. Future experiments are required to identity the $\mathrm{CaV} 3$ isoform(s) and the inherent mechanisms responsible for the increased activity of T-type calcium channels responsible for driving SCI-nociceptors to a hyperexcitable state.

\section{References}

Ali Z, Ringkamp M, Hartke TV, Chien HF, Flavahan NA, Campbell JN, Meyer RA (1999) Uninjured C-fiber nociceptors develop spontaneous activity and alpha-adrenergic sensitivity following L6 spinal nerve ligation in monkey. J Neurophysiol 81:455-466.

Andresen SR, Biering-Sørensen F, Hagen EM, Nielsen JF, Bach FW, Finnerup NB (2016) Pain, spasticity and quality of life in individuals with traumatic spinal cord injury in Denmark. Spinal Cord 54:973-979.

Basso DM, Beattie MS, Bresnahan JC (1995) A sensitive and reliable locomotor rating scale for open field testing in rats. J Neurotrauma 12:1-21.

Basso DM, Beattie MS, Bresnahan JC (1996) Graded histological and locomotor outcomes after spinal cord contusion using the NYU weight-drop device versus transection. Exp Neurol 139:244-256.

Bavencoffe A, Li Y, Wu Z, Yang Q, Herrera J, Kennedy EJ, Walters ET, Dessauer CW (2016) Persistent electrical activity in primary nociceptors after spinal cord injury is maintained by scaffolded adenylyl cyclase and protein kinase $\mathrm{A}$ and is associated with altered adenylyl cyclase regulation. J Neurosci 36:1660-1668.

Bedi SS, Yang Q, Crook RJ, Du J, Wu Z, Fishman HM, Grill RJ, Carlton SM, Walters ET (2010) Chronic spontaneous activity generated in the somata of primary nociceptors is associated with pain-related behavior after spinal cord injury. J Neurosci 30:14870-14882.

Blair NT, Bean BP (2002) Roles of tetrodotoxin (TTX)-sensitive Na+ current, TTX-resistant $\mathrm{Na}+$ current, and $\mathrm{Ca} 2+$ current in the action potentials of nociceptive sensory neurons. J Neurosci 22:10277-10290.

Bourinet E, Alloui A, Monteil A, Barrère C, Couette B, Poirot O, Pages A, McRory J, Snutch TP, Eschalier A, Nargeot J (2005) Silencing of the Cav3.2 T-type calcium channel gene in sensory neurons demonstrates its major role in nociception. EMBO J 24:315-324. 
Candelas M, Reynders A, Arango-Lievano M, Neumayer C, Fruquière A, Demes E, Hamid J, Lemmers C, Bernat C, Monteil A, Compan V, Laffray S, Inquimbert P, Le Feuvre Y, Zamponi GW, Moqrich A, Bourinet E, Méry PF (2019) Cav3.2 T-type calcium channels shape electrical firing in mouse lamina II neurons. Sci Rep 9:3112.

Carbone E, Lux HD (1984) A low voltage-activated, fully inactivating Ca channel in vertebrate sensory neurones. Nature 310:501-502.

Cardenas CG, Del Mar LP, Scroggs RS (1995) Variation in serotonergic inhibition of calcium channel currents in four types of rat sensory neurons differentiated by membrane properties. J Neurophysiol 74:1870-1879.

Cardenas CG, Del Mar LP, Cooper BY, Scroggs RS (1997) 5HT4 receptors couple positively to tetrodotoxin-insensitive sodium channels in a subpopulation of capsaicin-sensitive rat sensory neurons. J Neurosci 17:71817189.

Carlton SM, Du J, Tan HY, Nesic O, Hargett GL, Bopp AC, Yamani A, Lin Q, Willis WD, Hulsebosch CE (2009) Peripheral and central sensitization in remote spinal cord regions contribute to central neuropathic pain after spinal cord injury. Pain 147:265-276.

Caterina MJ, Schumacher MA, Tominaga M, Rosen TA, Levine JD, Julius D (1997) The capsaicin receptor: a heat-activated ion channel in the pain pathway. Nature 389:816-824.

Chen W, Chi YN, Kang XJ, Liu QY, Zhang HL, Li ZH, Zhao ZF, Yang Y, Su L, Cai J, Liao FF, Yi M, Wan Y, Liu FY (2018) Accumulation of Cav3.2 Ttype calcium channels in the uninjured sural nerve contributes to neuropathic pain in rats with spared nerve injury. Front Mol Neurosci 11:24.

Choe W, Messinger RB, Leach E, Eckle VS, Obradovic A, Salajegheh R, Jevtovic-Todorovic V, Todorovic SM (2011) TTA-P2 is a potent and selective blocker of T-type calcium channels in rat sensory neurons and a novel antinociceptive agent. Mol Pharmacol 80:900-910.

Choi S, Yu E, Hwang E, Llinás RR (2016) Pathophysiological implication of CaV3.1 T-type Ca2 + channels in trigeminal neuropathic pain. Proc Natl Acad Sci USA 113:2270-2275.

Cohen SP, Mao J (2014) Neuropathic pain: mechanisms and their clinical implications. BMJ 348:f7656.

Coste B, Crest M, Delmas P (2007) Pharmacological dissection and distribution of NaN/Nav1.9, T-type Ca2+ currents, and mechanically activated cation currents in different populations of DRG neurons. J Gen Physiol 129:57-77.

Cragg JJ, Noonan VK, Noreau L, Borisoff JF, Kramer JK (2015) Neuropathic pain, depression, and cardiovascular disease: a national multicenter study. Neuroepidemiology 44:130-137.

Davoody L, Quiton RL, Lucas JM, Ji Y, Keller A, Masri R (2011) Conditioned place preference reveals tonic pain in an animal model of central pain. J Pain 12:868-874.

Detloff MR, Wade RE Jr, Houlé JD (2013) Chronic at- and below-level pain after moderate unilateral cervical spinal cord contusion in rats. J Neurotrauma 30:884-890.

Dib-Hajj SD, Cummins TR, Black JA, Waxman SG (2010) Sodium channels in normal and pathological pain. Annu Rev Neurosci 33:325-347.

Dirajlal S, Pauers LE, Stucky CL (2003) Differential response properties of IB (4)-positive and -negative unmyelinated sensory neurons to protons and capsaicin. J Neurophysiol 89:513-524.

Djouhri L, Koutsikou S, Fang X, McMullan S, Lawson SN (2006) Spontaneous pain, both neuropathic and inflammatory, is related to frequency of spontaneous firing in intact C-fiber nociceptors. J Neurosci 26:1281-1292.

Do MT, Bean BP (2003) Subthreshold sodium currents and pacemaking of subthalamic neurons: modulation by slow inactivation. Neuron 39:109120

Finnerup NB (2013) Pain in patients with spinal cord injury. Pain 154 [Suppl 1]:S71-S76.

Finnerup NB, Johannesen IL, Sindrup SH, Bach FW, Jensen TS (2001) Pain and dysesthesia in patients with spinal cord injury: a postal survey. Spinal Cord 39:256-262.

Finnerup NB, Norrbrink C, Trok K, Piehl F, Johannesen IL, Sørensen JC, Jensen TS, Werhagen L (2014) Phenotypes and predictors of pain following traumatic spinal cord injury: a prospective study. J Pain 15:40-48.

Glaser ST, Kaczocha M (2010) Cyclooxygenase-2 mediates anandamide metabolism in the mouse brain. J Pharmacol Exp Ther 335:380-388.

Gorodetskaya N, Constantin C, Jänig W (2003) Ectopic activity in cutaneous regenerating afferent nerve fibers following nerve lesion in the rat. Eur J Neurosci 18:2487-2497.
Griggs RB, Bardo MT, Taylor BK (2015) Gabapentin alleviates affective pain after traumatic nerve injury. Neuroreport 26:522-527.

Hains BC, Klein JP, Saab CY, Craner MJ, Black JA, Waxman SG (2003) Upregulation of sodium channel Nav1.3 and functional involvement in neuronal hyperexcitability associated with central neuropathic pain after spinal cord injury. J Neurosci 23:8881-8892.

Ho C, O'Leary ME (2011) Single-cell analysis of sodium channel expression in dorsal root ganglion neurons. Mol Cell Neurosci 46:159-166.

Jacus MO, Uebele VN, Renger JJ, Todorovic SM (2012) Presynaptic Cav3.2 channels regulate excitatory neurotransmission in nociceptive dorsal horn neurons. J Neurosci 32:9374-9382.

Jagodic MM, Pathirathna S, Nelson MT, Mancuso S, Joksovic PM, Rosenberg ER, Bayliss DA, Jevtovic-Todorovic V, Todorovic SM (2007) Cell-specific alterations of T-type calcium current in painful diabetic neuropathy enhance excitability of sensory neurons. J Neurosci 27:33053316.

Jagodic MM, Pathirathna S, Joksovic PM, Lee W, Nelson MT, Naik AK, Su P, Jevtovic-Todorovic V, Todorovic SM (2008) Upregulation of the Ttype calcium current in small rat sensory neurons after chronic constrictive injury of the sciatic nerve. J Neurophysiol 99:3151-3156.

Jensen MP, Chodroff MJ, Dworkin RH (2007) The impact of neuropathic pain on health-related quality of life: review and implications. Neurology 68:1178-1182

Joksimovic SL, Joksimovic SM, Tesic V, García-Caballero A, Feseha S, Zamponi GW, Jevtovic-Todorovic V, Todorovic SM (2018) Selective inhibition of $\mathrm{Ca}_{\mathrm{V}} 3.2$ channels reverses hyperexcitability of peripheral nociceptors and alleviates postsurgical pain. Sci Signal 11:eaao4425.

Kang XJ, Chi YN, Chen W, Liu FY, Cui S, Liao FF, Cai J, Wan Y (2018) Increased expression of CaV3.2 T-type calcium channels in damaged DRG neurons contributes to neuropathic pain in rats with spared nerve injury. Mol Pain 14:1744806918765808.

Khaliq ZM, Bean BP (2010) Pacemaking in dopaminergic ventral tegmental area neurons: depolarizing drive from background and voltage-dependent sodium conductances. J Neurosci 30:7401-7413.

King T, Vera-Portocarrero L, Gutierrez T, Vanderah TW, Dussor G, Lai J, Fields HL, Porreca F (2009) Unmasking the tonic-aversive state in neuropathic pain. Nat Neurosci 12:1364-1366.

Messinger RB, Naik AK, Jagodic MM, Nelson MT, Lee WY, Choe WJ, Orestes P, Latham JR, Todorovic SM, Jevtovic-Todorovic V (2009) In vivo silencing of the $\mathrm{Ca}(\mathrm{V}) 3.2 \mathrm{~T}$-type calcium channels in sensory neurons alleviates hyperalgesia in rats with streptozocin-induced diabetic neuropathy. Pain 145:184-195.

Meyer RA, Raja SN, Campbell JN, Mackinnon SE, Dellon AL (1985) Neural activity originating from a neuroma in the baboon. Brain Res 325:255260.

Michaelis M, Blenk KH, Jänig W, Vogel C (1995) Development of spontaneous activity and mechanosensitivity in axotomized afferent nerve fibers during the first hours after nerve transection in rats. J Neurophysiol 74:1020-1027.

Mintz IM, Adams ME, Bean BP (1992) P-type calcium channels in rat central and peripheral neurons. Neuron 9:85-95.

Na HS, Choi S, Kim J, Park J, Shin HS (2008) Attenuated neuropathic pain in Cav3.1 null mice. Mol Cells 25:242-246.

Nagy JI, Hunt SP (1982) Fluoride-resistant acid phosphatase-containing neurones in dorsal root ganglia are separate from those containing substance P or somatostatin. Neuroscience 7:89-97.

Nelson MT, Joksovic PM, Perez-Reyes E, Todorovic SM (2005) The endogenous redox agent L-cysteine induces $\mathrm{T}$-type $\mathrm{Ca} 2+$ channel-dependent sensitization of a novel subpopulation of rat peripheral nociceptors. J Neurosci 25:8766-8775.

Obradovic A, Hwang SM, Scarpa J, Hong SJ, Todorovic SM, JevtovicTodorovic V (2014) CaV3.2 T-type calcium channels in peripheral sensory neurons are important for mibefradil-induced reversal of hyperalgesia and allodynia in rats with painful diabetic neuropathy. PLoS One 9: e91467.

Odem MA, Bavencoffe AG, Cassidy RM, Lopez ER, Tian J, Dessauer CW, Walters ET (2018) Isolated nociceptors reveal multiple specializations for generating irregular ongoing activity associated with ongoing pain. Pain 159:2347-2362.

Pan B, Yu H, Fischer GJ, Kramer JM, Hogan QH (2016) Dorsal root ganglionic field stimulation relieves spontaneous and induced neuropathic pain in rats. J Pain 17:1349-1358. 
Perez-Reyes E (2003) Molecular physiology of low-voltage-activated t-type calcium channels. Physiol Rev 83:117-161.

Petruska JC, Napaporn J, Johnson RD, Gu JG, Cooper BY (2000) Subclassified acutely dissociated cells of rat DRG: histochemistry and patterns of capsaicin-, proton-, and ATP-activated currents. J Neurophysiol 84:2365-2379.

Puopolo M, Bean BP, Raviola E (2005) Spontaneous activity of isolated dopaminergic periglomerular cells of the main olfactory bulb. J Neurophysiol 94:3618-3627.

Puopolo M, Raviola E, Bean BP (2007) Roles of subthreshold calcium current and sodium current in spontaneous firing of mouse midbrain dopamine neurons. J Neurosci 27:645-656.

Raman IM, Bean BP (1999) Ionic currents underlying spontaneous action potentials in isolated cerebellar Purkinje neurons. J Neurosci 19:16631674.

Renganathan M, Cummins TR, Waxman SG (2001) Contribution of Na(v) 1.8 sodium channels to action potential electrogenesis in DRG neurons. J Neurophysiol 86:629-640.

Ritter DM, Zemel BM, Hala TJ, O'Leary ME, Lepore AC, Covarrubias M (2015) Dysregulation of Kv3.4 channels in dorsal root ganglia following spinal cord injury. J Neurosci 35:1260-1273.

Rose KE, Lunardi N, Boscolo A, Dong X, Erisir A, Jevtovic-Todorovic V, Todorovic SM (2013) Immunohistological demonstration of CaV3.2 Ttype voltage-gated calcium channel expression in soma of dorsal root ganglion neurons and peripheral axons of rat and mouse. Neuroscience 250:263-274.

Rush AM, Cummins TR, Waxman SG (2007) Multiple sodium channels and their roles in electrogenesis within dorsal root ganglion neurons. J Physiol 579:1-14.

Rzhepetskyy Y, Lazniewska J, Proft J, Campiglio M, Flucher BE, Weiss N (2016) A Cav3.2/Stac1 molecular complex controls T-type channel expression at the plasma membrane. Channels (Austin) 10:346-354.

Shin JB, Martinez-Salgado C, Heppenstall PA, Lewin GR (2003) A T-type calcium channel required for normal function of a mammalian mechanoreceptor. Nat Neurosci 6:724-730.

Shipe WD, Barrow JC, Yang ZQ, Lindsley CW, Yang FV, Schlegel KAS, Shu Y, Rittle KE, Bock MG, Hartman GD, Tang C, Ballard JE, Kuo Y, Adarayan ED, Prueksaritanont T, Zrada MM, Uebele VN, Nuss CE, Connolly TM, et al. (2008) Design, synthesis, and evaluation of a novel 4aminomethyl-4-fluoropiperidine as a T-type $\mathrm{Ca} 2+$ channel antagonist. J Med Chem 51:3692-3695.

Siddall PJ, Loeser JD (2001) Pain following spinal cord injury. Spinal Cord 39:63-73.

Siddall PJ, McClelland JM, Rutkowski SB, Cousins MJ (2003) A longitudinal study of the prevalence and characteristics of pain in the first 5 years following spinal cord injury. Pain 103:249-257.

Silverman JD, Kruger L (1990) Selective neuronal glycoconjugate expression in sensory and autonomic ganglia: relation of lectin reactivity to peptide and enzyme markers. J Neurocytol 19:789-801.

Simms BA, Zamponi GW (2014) Neuronal voltage-gated calcium channels: structure, function, and dysfunction. Neuron 82:24-45.

Snutch TP, Zamponi GW (2018) Recent advances in the development of Ttype calcium channel blockers for pain intervention. Br J Pharmacol 175:2375-2383.

Störmer S, Gerner HJ, Grüninger W, Metzmacher K, Föllinger S, Wienke C, Aldinger W, Walker N, Zimmermann M, Paeslack V (1997) Chronic pain/dysaesthesiae in spinal cord injury patients: results of a multicentre study. Spinal Cord 35:446-455.

Stucky CL, Lewin GR (1999) Isolectin B(4)-positive and -negative nociceptors are functionally distinct. J Neurosci 19:6497-6505.

Taddese A, Bean BP (2002) Subthreshold sodium current from rapidly inactivating sodium channels drives spontaneous firing of tuberomammillary neurons. Neuron 33:587-600.

Talley EM, Cribbs LL, Lee JH, Daud A, Perez-Reyes E, Bayliss DA (1999) Differential distribution of three members of a gene family encoding low voltage-activated (T-type) calcium channels. J Neurosci 19:1895-1911.

Todorovic SM, Jevtovic-Todorovic V (2006) The role of T-type calcium channels in peripheral and central pain processing. CNS Neurol Disord Drug Targets 5:639-653.
Todorovic SM, Jevtovic-Todorovic V (2013) Neuropathic pain: role for presynaptic T-type channels in nociceptive signaling. Pflugers Arch 465:921-927.

Todorovic SM, Jevtovic-Todorovic V (2014) Targeting of CaV3.2 T-type calcium channels in peripheral sensory neurons for the treatment of painful diabetic neuropathy. Pflugers Arch 466:701-706.

Todorovic SM, Jevtovic-Todorovic V, Meyenburg A, Mennerick S, PerezReyes E, Romano C, Olney JW, Zorumski CF (2001) Redox modulation of T-type calcium channels in rat peripheral nociceptors. Neuron 31:7585.

Tomita S, Sekiguchi F, Deguchi T, Miyazaki T, Ikeda Y, Tsubota M, Yoshida S, Nguyen HD, Okada T, Toyooka N, Kawabata A (2019) Critical role of Cav3.2 T-type calcium channels in the peripheral neuropathy induced by bortezomib, a proteasome-inhibiting chemotherapeutic agent, in mice. Toxicology 413:33-39.

Velly AM, Mohit S (2018) Epidemiology of pain and relation to psychiatric disorders. Prog Neuropsychopharmacol Biol Psychiatry 87:159-167.

Walters ET (2012) Nociceptors as chronic drivers of pain and hyperreflexia after spinal cord injury: an adaptive-maladaptive hyperfunctional state hypothesis. Front Physiol 3:309.

Walters ET (2014) Neuroinflammatory contributions to pain after SCI: roles for central glial mechanisms and nociceptor-mediated host defense. Exp Neurol 258:48-61.

Wang D, Ragnarsson L, Lewis RJ (2019) Insight into T-type calcium channel structure, function and modulation. Curr Med Chem 27:3098-3122.

Watanabe M, Ueda T, Shibata Y, Kumamoto N, Shimada S, Ugawa S (2015) Expression and regulation of Cav3.2 T-type calcium channels during inflammatory hyperalgesia in mouse dorsal root ganglion neurons. PLoS One 10:e0127572.

Waxman SG, Zamponi GW (2014) Regulating excitability of peripheral afferents: emerging ion channel targets. Nat Neurosci 17:153-163.

Weiss N, Zamponi GW (2019) T-type calcium channels: from molecule to therapeutic opportunities. Int J Biochem Cell Biol 108:34-39.

Wen XJ, Li ZJ, Chen ZX, Fang ZY, Yang CX, Li H, Zeng YM (2006) Intrathecal administration of Cav3.2 and Cav3.3 antisense oligonucleotide reverses tactile allodynia and thermal hyperalgesia in rats following chronic compression of dorsal root of ganglion. Acta Pharmacol Sin 27:1547-1552.

Wen XJ, Xu SY, Chen ZX, Yang CX, Liang H, Li H (2010) The roles of Ttype calcium channel in the development of neuropathic pain following chronic compression of rat dorsal root ganglia. Pharmacology 85:295300 .

Werhagen L, Budh CN, Hultling C, Molander C (2004) Neuropathic pain after traumatic spinal cord injury-relations to gender, spinal level, completeness, and age at the time of injury. Spinal Cord 42:665-673.

White G, Lovinger DM, Weight FF (1989) Transient low-threshold Ca2+ current triggers burst firing through an afterdepolarizing potential in an adult mammalian neuron. Proc Natl Acad Sci USA 86:6802-6806.

Wu Z, Yang Q, Crook RJ, O’Neil RG, Walters ET (2013) TRPV1 channels make major contributions to behavioral hypersensitivity and spontaneous activity in nociceptors after spinal cord injury. Pain 154:2130-2141.

Wu Z, Li L, Xie F, Du J, Zuo Y, Frost JA, Carlton SMPD, Walters ET, Yang Q (2017) Activation of KCNQ channels suppresses spontaneous activity in DRG neurons and reduces chronic pain after spinal cord injury. J Neurotrauma 34:1260-1270.

Xu J, Brennan TJ (2010) Guarding pain and spontaneous activity of nociceptors after skin versus skin plus deep tissue incision. Anesthesiology 112:153-164.

Yang Q, Wu Z, Hadden JK, Odem MA, Zuo Y, Crook RJ, Frost JA, Walters ET (2014) Persistent pain after spinal cord injury is maintained by primary afferent activity. J Neurosci 34:10765-10769.

Yoshimura N, de Groat WC (1997) Plasticity of $\mathrm{Na}+$ channels in afferent neurones innervating rat urinary bladder following spinal cord injury. J Physiol 503:269-276.

Yue J, Liu L, Liu Z, Shu B, Zhang Y (2013) Upregulation of T-type Ca2+ channels in primary sensory neurons in spinal nerve injury. Spine 38:463-470.

Zhang Y, Jiang X, Snutch TP, Tao J (2013) Modulation of low-voltage-activated T-type $\mathrm{Ca}(2)(+)$ channels. Biochim Biophys Acta 1828:1550-1559. 